\title{
ANTIMICROBIAL AND PHYSICOCHEMICAL PROPERTIES OF METHYLCELLULOSE AND CHITOSAN FILMS CONTAINING A PRESERVATIVE
}

\author{
MAU-CHANG CHEN, GENE HORNG-CHIN YEH \\ and BEEN-HUANG CHIANG ${ }^{\prime}$
}

\author{
Graduate Institute of Food Science \\ and Technology \\ National Taiwan University \\ Taipei, Taiwan, R.O.C.
}

Accepted for Publication May 17, 1996

\begin{abstract}
The methylcellulose was mixed with chitosan as well as $4 \%$ of sodium benzoate or potassium sorbate to form a film. Investigations of the antimycotic activity of the film on Penicillium notatum and Rhodotorula rubra revealed that it possessed significant antifungal properties. At 25C, approximately $43-45 \%$ of the preservatives were released from the film to the glycerol-water mixture in the first $30 \mathrm{~min}$. The maximum amount of preservative that could be released from the film at $25 \mathrm{C}$ was approximately $57-65 \%$. At $4 \mathrm{C}, 38-39 \%$ of preservatives were released from the film within $30 \mathrm{~min}$, and reached a maximum amount of $49 \%$ in approximately $6 \mathrm{~h}$. The FT-IR spectrum showed that the ionic interaction between - $\mathrm{COO}$ of preservatives and $-\mathrm{NH}_{3}+$ of chitosan existed in the film. However, the incorporation of preservatives did not affect the tensile strength and elongation property of the methylcellulose/chitosan film.
\end{abstract}

\section{INTRODUCTION}

The concept of "active packaging" has evolved many technologies for food preservation (Labuza and Breene 1989). The antimicrobial film is a type of active package such that the preservative released from the film deposits on the food surface and inhibits the microbial growth. A few reports concerning the antimicrobial film exist in the literature. The Farbwerke Hoechst Company of Germany (French patent No. 1557.949, 1967) coated sorbic acid on a polyethylene film $\left(2-5 \mathrm{~g} / \mathrm{m}^{2}\right)$ to extend shelf-life of packaged foods. Ghosh $e t$ al. (1977) developed a fungistatic wrapper made by coating grease paper with an aqueous dispersion of sorbic acid in $2 \%$ carboxylmethylcellulose, and observed

1 Correspondent.

Journal of Food Processing and Preservation 20 (1996) 379-390. All Rights Reserved.

Copyright 1996 by Food \& Nutrition Press, Inc., Trumbull, CT 06611 
that food could be preserved for a minimum of 10 days by simply wrapping it in the treated paper and further enclosing it in a polyethylene bag. The Dai Nippon Printing Company of Japan introduced an antimicrobial film (Ando et al. 1988). This film contains Zeolite, a metal containing aluminosilicate, which releases active oxygen to inhibit microbial activity in the packaged food. Many recent studies along the similar line, however, have focused on edible film. The edible film was coated on the food surface which prevented the diffusion of later applied preservative into the food, thus inhibiting the surface microorganisms (Vojdani and Torres 1989; Torres et al. 1985).

Direct incorporation of preservative into the film is an economical method for manufacturing antimicrobial packaging. However, the interaction between the preservatives and film forming material may affect the film casting, release of preservative and mechanical properties of the film. In this study, an antimicrobial film has been prepared by using the mixnure of methylcellulose, chitosan and preservatives. Historically, cellulose and its derivative have yielded high quality films owning to the linear structure of the polymer backbone (Krumel and Lindsay 1976). However, a preliminary study revealed that methylcellulose film was readily dissolved in water. But, a mixture of methylcellulose and chitosan could yield a complex film with better water resistance. In addition, chitosan itself possesses antimicrobial property (Leuba and Stossel 1986; Hadwiger et al. 1986), and it may also provide the film with controlled release property (Miyazaki et al. 1981; Kawashima et al. 1985). However, the chitosan may also interact with the methylcellulose and preservatives which possess anionic groups (Mireles et al. 1992), thereby alters the physicochemical properties of the film and inhibit the release of preservatives. The main objectives of this study were to investigate the physicochemical and antimycotic properties of the methylcellulose/chitosan complex film incorporated with preservative in order to determine its efficacy as a potential "active packaging" material.

\section{MATERIALS AND METHODS}

\section{Raw Materials and Reagents}

Methylcellulose, potassium sorbate, sodium benzoate, and polyethylene glycol 400 were purchased from Sigma Co. (St. Louis, MO.). Other reagents included sorbic acid, benzoic acid (Merck Co. Darmstadt, F.R. Germany); acetic acid (ALPS Chem Co., Ltd., Taiwan); glycerol (Hayashi Pure Chemical Industries, Ltd. Osaka, Japan).

\section{Chitosan Preparation}

Crab shell was initially oven dried, ground and then passed through a 20 
mesh screener. The particles were soaked overnight in $0.5 \mathrm{~N} \mathrm{NaOH}$ solution at room temperature to remove the adhered surface meat. After washing with water to neutrality, they were treated with $2 \mathrm{~N} \mathrm{NaOH}$ at $80 \mathrm{C}$ for $2 \mathrm{~h}$ to remove protein. The crab chitin thus obtained was allowed to react with $45 \% \mathrm{NaOH}$ solution $(\mathrm{NaOH}$ soln/crab shell chitin $\mathrm{V} / \mathrm{W}=30 / 1)$ for $1 \mathrm{~h}$ at $100 \mathrm{C}$ to obtain 75\% deacetylated chitosan (Chen 1987).

\section{Preparation of Solutions for Forming the Film}

Solution A. Methylcellulose ( $4.5 \mathrm{~g}$ ) and appropriate amount of preservative were mixed with $50 \mathrm{~mL}$ of hot water (ca $90 \mathrm{C}$ ) and stirred until a uniform suspension was obtained. Further, $100 \mathrm{~mL}$ of ethanol and $0.5 \mathrm{~mL}$ of polyethylene glycol were added into the above suspension which was then heated to $80 \mathrm{C}$ and agitated for approximately $15 \mathrm{~min}$ to form solution $\mathrm{A}$.

Solution B. Chitosan $(1 \mathrm{~g})$ and appropriate amount of preservative were dissolved in $100 \mathrm{~mL}$ of $1.5 \%$ acetic acid solution to form solution B.

Solution C. Solutions A and B were mixed in a ratio of 3:2 (v:v) to form solution C.

Following their preparation, the apparent viscosities (expressed in CPS) of these solutions were determined by the Brookfield synchroelectric viscometer (Model DVII, Brookfield Engineering Lab., Stoughton, MA) at 25C using LVF No. 4 spindle rotating at $30 \mathrm{rpm}$.

\section{Preparation of Antimicrobial Films}

The methylcellulose antimicrobial film was prepared by spreading solution A on a glass plate $(20 \times 20 \mathrm{~cm})$ with a $2 \mathrm{~mm}$ spacer (Kamper and Fennema 1984). The film was dried on the plate at $80 \mathrm{C}$ for $20 \mathrm{~min}$ in an oven. After cooling, the film was peeled off from the plate, packed in a polyethylene bag and stored at room temperature for 3 to 4 days before use.

The antimicrobial chitosan film was prepared by spreading solution $B$ on the glass plate with a $4 \mathrm{~mm}$ spacer. The film was first dried on the plate at $80 \mathrm{C}$ for $2 \mathrm{~h}$ and then allowed to set for 2 days at room temperature before peeling.

For the preparation of complex antimicrobial film, solution $\mathrm{C}$ was spread on the glass plate, dried on the plate at $80 \mathrm{C}$ for $1 \mathrm{~h}$ and then allowed to set for 2 days at room temperature before peeling.

\section{Rates of Release of Preservatives from Methylcellulose/Chitosan Films}

A water-glycerol solution prepared by mixing equal weight of distilled water and glycerol (W:W = 1:1) was used for preservative release rate study (Guilbert 
et al. 1985; Giannkopoulos and Guilbert 1986). The water activity of the mixture was 0.80 as measured by a water activity analyzer (Novasina Thermoconstanter TH2/RTD-33/BSK, Defensor Co., Switzerland). The $50 \mathrm{mg}$ of antimicrobial films were immersed in the water-glycerol solutions either at $4 \mathrm{C}$ or $25 \mathrm{C}$. Sample solutions were taken periodically for analyzing the preservative content in the solutions. For determining the rates of release of preservatives from films to medium at $25 \mathrm{C}$ and various $\mathrm{pH}, 50 \mathrm{mg}$ of films were immersed in the water-glycerol solution which was adjusted to $\mathrm{pH} 3$ or 6 by $\mathrm{NaOH}$ or $\mathrm{HCl}$ solution, respectively. The potassium sorbate and sodium benzoate concentrations in the water-glycerol solution were determined spectrophotometrically at $257 \mathrm{~nm}$ and $224 \mathrm{~nm}$, respectively (Rico-Pena and Torres 1991) (UV/VIS spectrophotometer, Spectronic 300 array, Milton Roy, Rochester, NY).

\section{Determination of Antimicrobial Effect of Film}

The agar diffusion test was used for determining the antimicrobial effect of films on microorganisms (Ellerman 1977; Halek and Gary 1989). The test organisms used were Rhodotorula rubra (CBS7014) and Penicillium notatum (ATCC, 11625). Both of the test organisms were supplied by the Food Industry Research and Development Institute (Shingchu, Taiwan). The $R$. rubra was first inoculated on a YM agar (Difco. Lab. Detroit, MI) slope, and incubated at 24C for $48 \mathrm{~h}$. About $3 \mathrm{~mL}$ of sterile water was then transferred to the slope for suspending the growth and $0.1 \mathrm{~mL}$ of the suspension was spread evenly on a YM agar plate to form the assay plate. For $P$. notatum, the test organism was inoculated on a potato dextrose agar (PDA) slope. After incubating at $24 \mathrm{C}$ for $48 \mathrm{~h}$, appropriate amount of sterile water, containing $0.01 \%$ Tween - 80 (Sigma Co., St. Louis, MO.) as surfactant, was added to suspend the growth. The 0.1 $\mathrm{mL}$ of suspension was then spread on PDA plate to obtain the assay plate.

The antimicrobial films were then cut into 1.5 in. diameter discs, placed on the assay plate and incubated at $24 \mathrm{C}, 90 \% \mathrm{RH}$ for $72 \mathrm{~h}$. The antimicrobial effect of the film was determined by observing the existence of clear zone at the contact area as well as around the discs.

The Fourier Transform Infrared (FT-IR) spectrometry was employed to analyze the functional groups of the film in order to determine the possible interactions between preservatives and chitosan. At $28 \pm 1 \mathrm{C}, 55 \pm 5 \%$ relative humidity, the transmittance of the chitosan and chitosan/preservative films between 500 and $4000 \mathrm{~cm}^{-1}$ was measured using the FT-IR spectrometer (Model No. FTS-40, Biorad Co., Boston).

\section{Determination of Physical Properties of Antimicrobial Films}

The thickness of the films was measured using a micrometer (Type SMD540, Teclock Co., Japan). At least five measurements were taken for each film. 
The mechanical strength of the antimicrobial films $(25 \times 100 \mathrm{~mm}$, thickness $50 \pm 5 \mu \mathrm{m}$ ) was measured by using Instron (Series IX, automated materials testing system I.II, Instron Co., Chicago). The tensile strength as well as rate of elongation of the films were both tested at $50 \mathrm{~mm} / \mathrm{min}$ of crosshead speed (Test Method A, ASTM, 1990). The measurements were performed on two sheets of film which were prepared separately. At least six samples were taken from each sheet of film for the measurements. The Duncan multiple range test was used for analyzing the data statistically (Duncan 1955).

\section{RESULTS AND DISCUSSION}

\section{Compatibility and Interactions among Preservatives, Methylcellulose and Chitosan}

Methylcellulose is known to be compatible with many water-soluble polymers, such as alginate, starch and polyvinyl alcohol (Grover 1986). Although chitosan is soluble only in acidic water solution, it also exhibited good compatibility with methylcellulose. In the present experiment, $\mathrm{pH}$ of the chitosan/methylcellulose mixture was 4.3 , while the amino group of chitosan (pKa 6.3-6.7) was positively charged and the carboxyl group of preservative was negatively charged (Rinaudo and Domard 1989). Thus, ionic interactions between preservative and chitosan are likely to exist, which are expected to reduce the intramolecular electrostatic repulsion in the chitosan molecules and facilitated formation of intramolecular hydrogen bonding. Consequently, the chitosan molecules might have a more compact structure, which resulted in lowering the viscosity of the solution due to the reduced friction between chitosan molecules (Kienzle-Sterzer et al. 1985; Rinaduo and Domard 1989). In addition, Grover (1986) has reported that the viscosity of methylcellulose solution would reduce as a result of increase in the concentration of electrolytes in the solution. Therefore, addition of preservative in the chitosan/methylcellulose mixture resulting in lowering the viscosity (Table 1) was not unexpected.

Figure 1 depicts the infrared spectra of chitosan film with as well as without preservatives. The absorption peaks around $2800 \mathrm{~cm}^{-1}$ (peak A), $1640 \mathrm{~cm}^{-1}$ (peak B), and $1560 \mathrm{~cm}^{-1}$ (peak C) corresponded to the $\mathrm{NH}_{3}{ }^{+}$stretching, asymmetric bending, and symmetric bending of chitosan, respectively. Although all three films showed absorption at $1380 \mathrm{~cm}^{-1}$ the chitosan films containing preservative had a relatively larger absorption peak at this wavenumber (peak D). Since the absorption at $1380 \mathrm{~cm}^{-1}$ corresponds to a symmetric carboxyl ion group (-coo) of preservative (Silverstein et al. 1991), the spectra suggested that the preservatives in the film were in the form of carboxylate anion. In addition, there was no absorption at $1710 \mathrm{~cm}^{-1}$ (the $\mathrm{C}=0$ stretch of the $-\mathrm{COOH}$ group) in 
TABLE 1.

EFFECT OF PRESERVATIVES ON THE VISCOSITY OF METHYLCELLULOSE AND CHITOSAN SOLUTIONS.

Kinds of solution

Chitosan

Methylcellulose

Chitosan/methylcellulose

Chitosan/methylcellulose + sodium benzoate (4\%)

Chitosan/methylcellulose + potassium sorbate (4\%)

Viscosity* $^{*}(25 \mathrm{C})(\mathrm{cps}) \times 10^{3}$
$1.7^{\mathrm{a}}$
$14.5^{\mathrm{bc}}$
$16.4^{\mathrm{b}}$
$14.2^{\mathrm{bc}}$
$13.2^{\mathrm{c}}$

abc Means superscripted with different letters are significantly different at $5 \%$ level.

- The Brookfield No. 4 spindle rotating at $30 \mathrm{rpm}$ was used for the viscosity measurement.

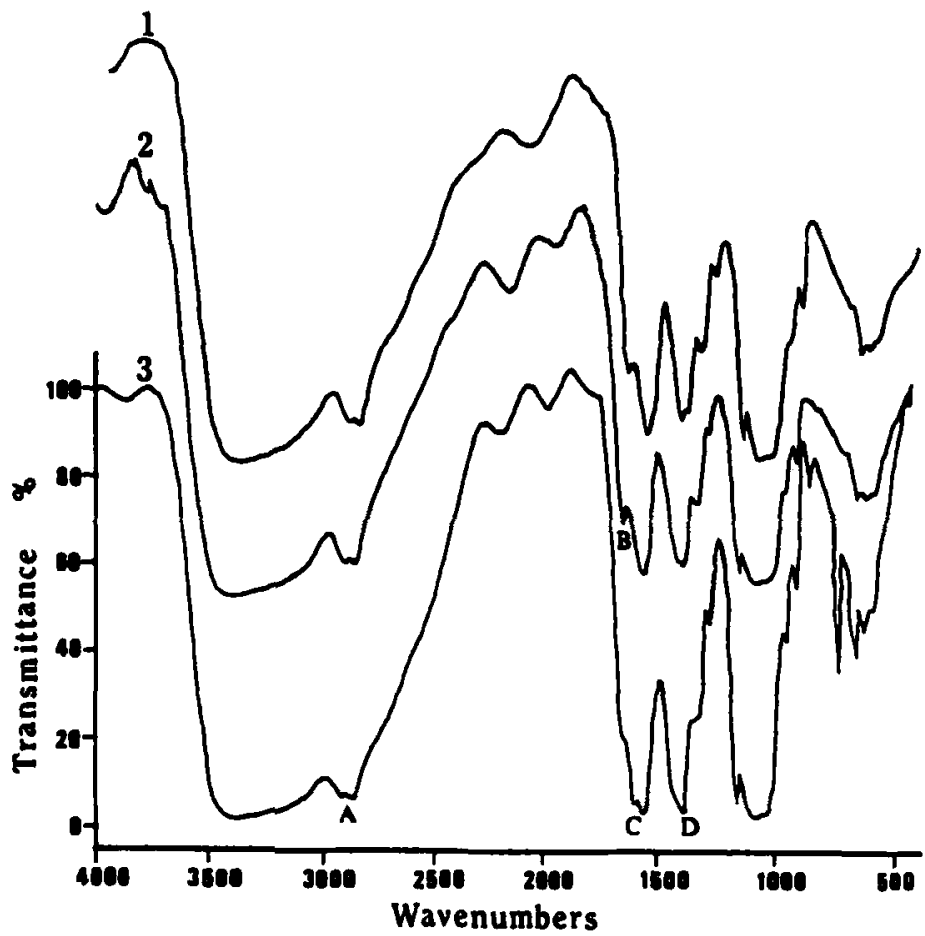

FIG. 1. INFRARED SPECTRA OF CHITOSAN FILMS INCORPORATED WITH SODIUM BENZOATE OR POTASSIUM SORBATE

1. Chitosan film; 2. chitosan/potassium sorbate film; 3. chitosan/sodium benzoate film. A. NH stretch $(2800 \mathrm{CM})$; B. asymmetric $\mathrm{NH}$ bend $(1640 \mathrm{CM})$; C. symmetric $\mathrm{NH}$ bend $(1560 \mathrm{CM})$; D. symmetric carboxy stretch (1380 CM). 
any of the spectrum in Fig. 1, which also implied that most of the carboxyl groups in the films existed as carboxylate anion (Samuels 1981). Based on the results of FTIR, it appeared that the possible electrostatic interaction between the amino group of chitosan and the carboxyl group of preservative could exist.

\section{Antimicrobial Properties of the Films}

The antimicrobial properties of the films were evaluated by noting whether there was inhibition of bacterial growth at the film/medium interface, along with the existence of clear inhibitory zone around the film after incubation. The results of these investigations revealed that the chitosan film itself could inhibit the microbial growth at the film/medium interface (Table 2). The antimicrobial property of chitosan is likely to be due to the interaction between the $\mathrm{NH}_{3}{ }^{+}$of chitosan and cell membrane, which results in altering the permeability of the

TABLE 2.

THE ANTIMICROBIAL ACTIVITIES OF THE FILMS MADE OF METHYLCELLULOSE, CHITOSAN AND PRESERVATIVES.

\begin{tabular}{lcc}
\hline Types of edible film & Inhibition of inhibitory zone & Contact area \\
\hline $\mathrm{CF}$ & + & - \\
$\mathrm{MF}$ & & - \\
$\mathrm{CF}+2 \%$ benzoate & + & - \\
$\mathrm{CF}+2 \%$ sorbate & + & - \\
$\mathrm{CF}+5 \%$ benzoate & + & + \\
$\mathrm{CF}+5 \%$ sorbate & + & + \\
$\mathrm{MF}+2 \%$ benzoate & + & + \\
$\mathrm{MF}+2 \%$ sorbate & + & + \\
$\mathrm{CF} / \mathrm{MF}$ & +1 & + \\
$\mathrm{CF} / \mathrm{MF}+4 \%$ benzoate & + & + \\
$\mathrm{CF} / \mathrm{MF}+4 \%$ sorbate & + & + \\
\hline $\mathrm{CF}:$ chitosan film & & \\
$\mathrm{MF}:$ methylcellulose film & \\
$\mathrm{CF} / \mathrm{MF}:$ chitosan and methylcellulose complex film & \\
$+\quad:$ represents an inhibitory effect &
\end{tabular}


membrane (Leuba and Stossel 1986). The methylcellulose films containing 2\% preservatives yielded clear zone at the film/medium interface as well as the area around the disc. However, the chitosan film containing $2 \%$ of preservative did not result in a clear inhibitory zone around the film disc. This observation could be attributed to the interaction between chitosan and preservatives and consequently prohibited the release of latter. The clear inhibitory zone was observed only until the concentration of preservatives in the chitosan film reached 5\%; presumably the binding sites for preservative in chitosan were saturated at this concentration. The complex film comprising of methylcellulose and chitosan, containing $4 \%$ preservatives, could release the antimicrobial agents and form clear inhibitory zone during incubation.

\section{Rate of Release of Preservatives from Film}

The main aim for the development of antimicrobial film is to inhibit growth of microorganisms on the surface of food. One of its major potential application lies in the storage of semimoist foods which contain $20-50 \%$ moisture. The rates of release of preservatives were hence measured in the water-glycerol solution at water activity of 0.8 (Guilbert et al. 1985; Giannakopoulos and Guilbert 1986; Rico-Pena and Torres 1991).

Regardless of the temperature difference, the initial rates of release of preservatives from the methylcellulose/chitosan complex film were observed to be high. It was noted that, within the first $30 \mathrm{~min}$, approximately $40 \%$ of the preservative in the film was released (Fig. 2 and 3). High initial rate of release of preservative could inhibit the microbial growth at the early stage of storage; however, it also resulted in a high preservative concentration at the food surface and hence increased its diffusion rate from the surface into the foodstuff due to the high concentration gradient. Such high diffusion rate might in turn reduce the antimicrobial effect of the film for long term storage. The chitosan in the film was supposed to provide the film with controlled release property (Miyazaki et al. 1981; Kawashima et al. 1985). The present result was, however, unsatisfactory. More detailed study along this line is deemed necessary.

At $4 \mathrm{C}$, the maximum amount of the preservative released from the film was approximately $50 \%$ and increased to $60 \%$ at $25 \mathrm{C}$. High temperature increases the solubility of the preservative, and probably weakens the ionic interaction between preservative and chitosan, thereby increasing the amount of preservative being released. The rates of release of preservatives at $\mathrm{pH} 3$ and $\mathrm{pH} 6$ were not significantly different $(\mathrm{P}<0.05)$. However, both sodium benzoate and potassium sorbate were mostly in the form of undissociated acid at low pH, whereas they were present in the form of salt at high $\mathrm{pH}$. Since only the acid form of preservative possesses antimicrobial effect, more preservatives may be incorporated into the antimicrobial film when the film is to be used for low acid foods. 


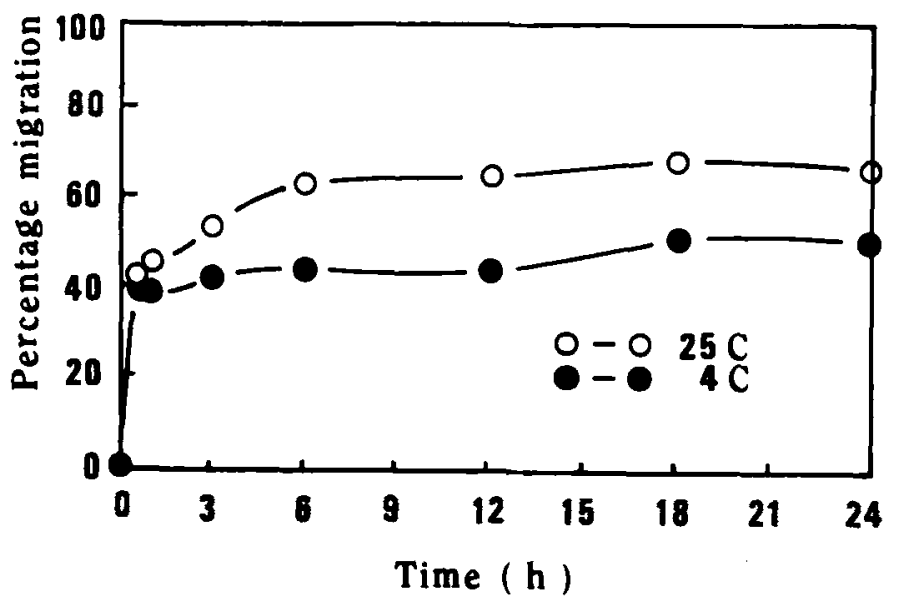

FIG. 2. EFFECT OF TEMPERATURE ON THE MIGRATION RATE OF SODIUM BENZOATE FROM THE METHYLCELLULOSE/CHITOSAN FLM INTO A GLYCEROL-WATER MIXTURE MODEL SYSTEM AT WATER ACTIVITY 0.8

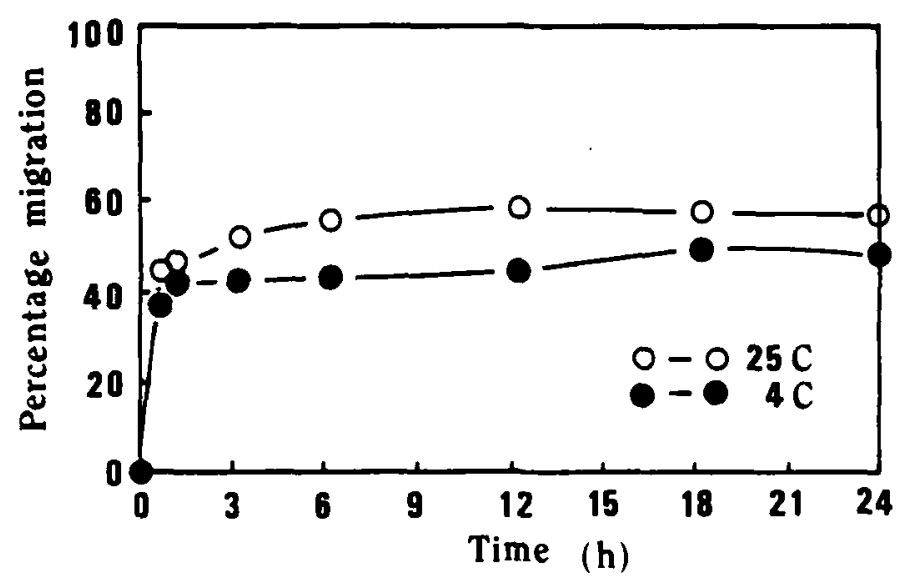

FIG. 3. EFFECT OF TEMPERATURE ON THE MIGRATION RATE OF POTASSIUM SORBATE FROM A METHYLCELLULOSE/CHITOSAN FILM INTO A GLYCEROLWATER MODEL SYSTEM AT WATER ACTIVITY 0.8 
Table 3 lists the tensile strength and elongation rate of the methylcellulose/ chitosan antimicrobial films. It was found that the mechanical properties of the films were not changed significantly $(P>0.05)$ because of the incorporation of preservatives. In general, the antimicrobial film showed relatively good tensile strength, but poor elongation property, as compared to the mechanical properties of commonly used plastic films.

TABLE 3.

EFFECT OF PRESERVATTVES ON THE MECHANICAL PROPERTIES OF THE FILMS MADE OF METHYLCELLULOSE, CHITOSAN, AND PRESERVATIVES

\begin{tabular}{lcc}
\hline \multicolumn{1}{c}{ Type of film } & Tensile strength & Elongation $\left(\mathrm{kg} / \mathrm{mm}^{2}\right)(\%)$ \\
\hline CF/MF & $2.8 \pm 0.2$ & $19.6 \pm 6.1$ \\
CF/MF+Benzoate(4\%) & $3.8 \pm 0.6$ & $28.5 \pm 6.8$ \\
CF/MF+Sorbate(4\%) & $3.0 \pm 0.1$ & $22.5 \pm 4.6$ \\
\hline
\end{tabular}

CF/MF: chitosan/methylcellulose composite film

* Means within the same column are not significantly different $(P>0.05)$

** Data were obtained by testing on the $50 \pm 5$ um (ca. 2 mil) film

\section{CONCLUSION}

In the present study, it has been observed that the packaging film prepared from methylcellulose, chitosan, and preservative possesses antimicrobial property. Although the rate of release of preservative from the film was too high to maintain a proper preservative concentration at food surface for a long period of time, the film also possesses antimicrobial activity when contacted with food, thereby extending the shelf-life of packaged foods.

It should also be pointed out that the release of preservative from the film depends on the migration of water or water vapor from food to the film in order to dissolve the preservative and facilitate its diffusion to the food surface. The film may hence be suitable only for those food items which have relatively high moisture content.

\section{ACKNOWLEDGMENT}

This research was supported by the National Science Council, ROC under the project No NSC81-0406-E-002-01. 


\section{REFERENCE}

ANDO, S., DONO, A., MITA, K., YAMADA, T., TOMIZAWA, T. and HAGIWARA, Z. 1988. Antimicrobial films containing metal ions, zeolite, absorbents and synthetic resins for food packaging. Japan patent 63154746.

ASTM, 1990. American Society for Testing and Materials: Standard test methods for tensile properties of thin plastic sheeting. ASTM designation: D882-90.

CHEN, H.Y. 1987. High value utilization of grass shrimp heads - Isolation, particle purification and application of protease. MS thesis, National Taiwan University.

DUNCAN D.B. 1955. Multiple range and multiple F tests. Biometrics 11, $1-42$.

ELLERMAN, J.A.G. 1977. Assay of sorbate and benzoate by the disc-plate method. Australian J. Dairy Technol. 32, 13-15.

GHOSH, K.G., SRIVATSA, A.N., NIRMALA, N. and SHARMA, T.R. 1977. Development and application of fungistat wrappers in food preservation. J. Food Sci. and Technol. 14, 261-264.

GIANNAKOPOULOS, A. and GUILBERT, S. 1986. Determination of sorbic acid diffusivity in model food gels. J. Food Technol. 21, 339-353.

GROVER, J.A. 1986. Methylcellulose and hydroxypropylmethylcellulose. In Food Hydrocolloids Vol. 3, Ch. 4 (M. Glicksman, ed.) pp. 121-154, CRC Press, Boca Raton, FL.

GUILBERT, S., GIANNAKOPOULOS, A. and CHEFTEL, J.C. 1985. Diffusivity of sorbic acid in food gels at high and intermediate water activities. In Properties of Water in Foods, (D. Simatos and J.L. Multon, eds.) pp. 343-356, Dordercht Martimus Nijhoff.

HADWIGER, L.A., KENDRA, D.F., FRISTENSKY, B.W. and WAGONER, W. 1986. Chitosan both activates genes in plants and inhibits RNA synthesis in fungi. In Chitin in Nature and Technology, (R. Muzzarelli, C. Jeuiaux and G.W. Gooday, eds.) pp. 209-222, Plenum Press, New York.

HALEK, G.W. and GARY, A. 1989. Fungal inhibition by a fungicide coupled to an ionomeric film. J. Food Safety, 9, 215-222.

KAMPER, S.L. and FENNEMA, O. 1984. Water vapor permeability of edible bilayer films. J. Food Sci. 49, 1478-1485.

KAWASHIMA, Y., HANDA, T., KASBI, A., TAKENAKA, H., LIN, S.Y. and ANDO, Y. 1985. The effects of thickness \& hardness of the coating film on the chitosan sodium tripolyphosphate complex. Chem. Pharm. Bull. 33, 2469-2474.

KAWASHIMA, Y., LIN. S.Y., KASAI, A., HANDA, T. and TAKENAKA, H. 1985. Chem. Pharm. Bull. 33(5), 2107-2113. 
KIENZLE-STERZER, C.A., RODRIQUEZ-SANCHEZ, D. and RHA, C.K. 1985. Flow behaviour of a cationic biopolymer: Chitosan. Polymer Bull. 13, 1-6.

KRUMEL, K.L. and LINSAY, T.A. 1976. Nonionic cellulose ethers. Food Technol. 30, 36-43.

LABUZA, T.P. and BREENE, M.W. 1989. Applications of "Active packaging" for improvement of shelf-life and nutritional quality of fresh and extended shelf-life foods. J. Food Processing Preservation 13, 1-69.

LEUBA, J.L. and STOSSEL, P. 1986. Chitosan and other polyamines: antifungal activity and interaction with biological membranes. In Chitin in Nature and Technology, (R. Muzzarelli, C. Jeuniaux and G.W. Gooday, eds.) pp. 215-222, Plenum Press, New York.

MIRELES, C., MARTINO, M., TORRES, J.A. and BOUZAS, J. 1992. Complex formation of chitosan and naturally occuring polyanions. In Advances in Chitin and Chitosan (C.J. Brine, ed.) pp. 506-515, Elsevier Applied Science, London.

MIYAZAKI, S., ISHH, K. and NADAI, T. 1981. The use of chitin and chitosan as drug carriers. Chem. Pharm. Bull. 29, 3067-3069.

RICO-PENA, D.C. and TORRES, J.A. 1991. Sorbic acid and potassium sorbate permeability of an edible methylcellulose-palmitic acid film: water activity and $\mathrm{pH}$ effects. J. Food Sci. 56, 497-499.

RINADUO, M. and DOMARD, A. 1989. Solution properties of chitosan. In Chitin and Chitosan, (G. Skjak-Braek, T. Anthonsen and P. Sandford, eds.) pp. 71-86, Elsevier Sci. Publishers.

SAMUELS, R.J. 1981. Solid state characterization of the structure of chitosan film. J. Polym. Sci. 19, 1081-1105.

SILVERSTEIN, R.M., BASSLER, G.C. and MORRILL, T.C. 1981. Infrared spectrometry. Ch. 3. In Spectrometric Identification of Organic Compounds, 4th ed. pp. 95-137, John Wiley \& Sons, New York.

TORRES, J.A., MOTOKI, M. and KAREL, M. 1985. Microbial stabilization of intermediate moisture food surfaces. I. Control of surface preservative concentration. J. Food Processing Preservation 9, 75-92.

UCHIDA, A. 1988. Antimicrobial properties of chitin and chitosan. Special issue: Natured antimicrobial agents and antioxidants. Food Chemical. Feb. pp. 22-29.

VOJDANI, F. and TORRES, J.A. 1989. Potassium sorbate permeability of methylcellulose and hydroxypropyl methylcellulose multi-layer films. J. Food Processing Preservation 13, 417-430. 